(Supporting Information)

\title{
Chiroptical and Lectin Recognition Properties of Glycoconjugated Poly(phenylacetylene)s Featuring Variable Saccharide Functionalities
}

\author{
Issei Otsuka, ${ }^{\dagger}$ Takayoshi Hongo, ${ }^{\dagger}$ Hiroshi Nakade,${ }^{\dagger}$ Atsushi Narumi,${ }^{\dagger}$ Ryosuke Sakai, ${ }^{\dagger}$ \\ Toshifumi Satoh, ${ }^{\dagger}$ Harumi Kaga, ${ }^{+}$and Toyoji Kakuchi ${ }^{\dagger} *$
}

${ }^{\dagger}$ Division of Biotechnology and Macromolecular Chemistry, Graduate School of Engineering, Hokkaido University, Sapporo, 060-8628, Japan; ${ }^{\ddagger}$ National Institute of Advanced Industrial Science and Technology (AIST), Sapporo, 062-8517, Japan

\section{Copolymerization of Phenylacetylene with PA- $\alpha$-Glc-OAc}

To a stirred solution of PA- $\alpha$-Glc-OAc $(0.50 \mathrm{~g}, 1.1 \mathrm{mmol})$ and phenylacetylene $(0.11 \mathrm{~g}, 1.1 \mathrm{mmol})$ in dry $\mathrm{CHCl}_{3}(15 \mathrm{~mL})$ was added a solution of $\mathrm{Rh}$ (norbornadiene) $\mathrm{BPh}_{4}(23 \mathrm{mg}, 45 \mu \mathrm{mol})$ in dry $\mathrm{CHCl}_{3}(7$ $\mathrm{mL}$ ) under an argon atmosphere. After $20 \mathrm{~h}$, the reaction was terminated by adding triphenylphosphine (70 $\mathrm{mg}, 0.27 \mathrm{mmol}$ ) and then poured into a large amount of methanol. The precipitate was filtered off and dried in vacuo to give a polymeric product as a yellow powder. The ${ }^{1} \mathrm{H}$ NMR spectrum of the resulting polymer consisted of characteristic signals due to the saccharide unit, aromatic group, and polymer main chain (Figure S-1). Thus, the obtained polymer was assigned to a copolymer of phenylacetylene and

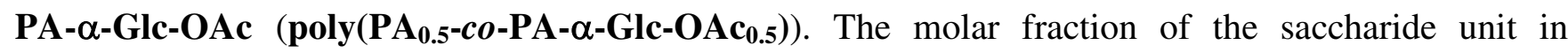
poly $\left(\mathrm{PA}_{0.5}-\mathrm{co}-\mathbf{P A}-\boldsymbol{\alpha}\right.$-Glc-OAc $\left.\mathbf{c}_{0.5}\right)\left(f_{\mathrm{s}}\right)$ was estimated to be 0.53 based on the area ratio between the signals due to the aromatic groups $(\delta$ 7.47-6.08) and those due to H-5 and H-6 of the saccharide units $(\delta$ 3.26-4.47). Yield: $91.4 \%, M_{\mathrm{n}}: 2.78 \times 10^{4} . M_{\mathrm{w}} / M_{\mathrm{n}}: 3.57$ (determined by SEC in $\mathrm{CHCl}_{3}$ using polystylene 
standards). ${ }^{1} \mathrm{H}$ NMR $\left(\mathrm{CDCl}_{3}\right): \delta$ 7.47-6.08 (br, aromatic), 5.99-4.78 (br, =CH and saccharide moiety), 4.47-3.26 (br, saccharide moiety), 2.60-1.73 (br, acetyl). $f_{\mathrm{s}}=0.53$.

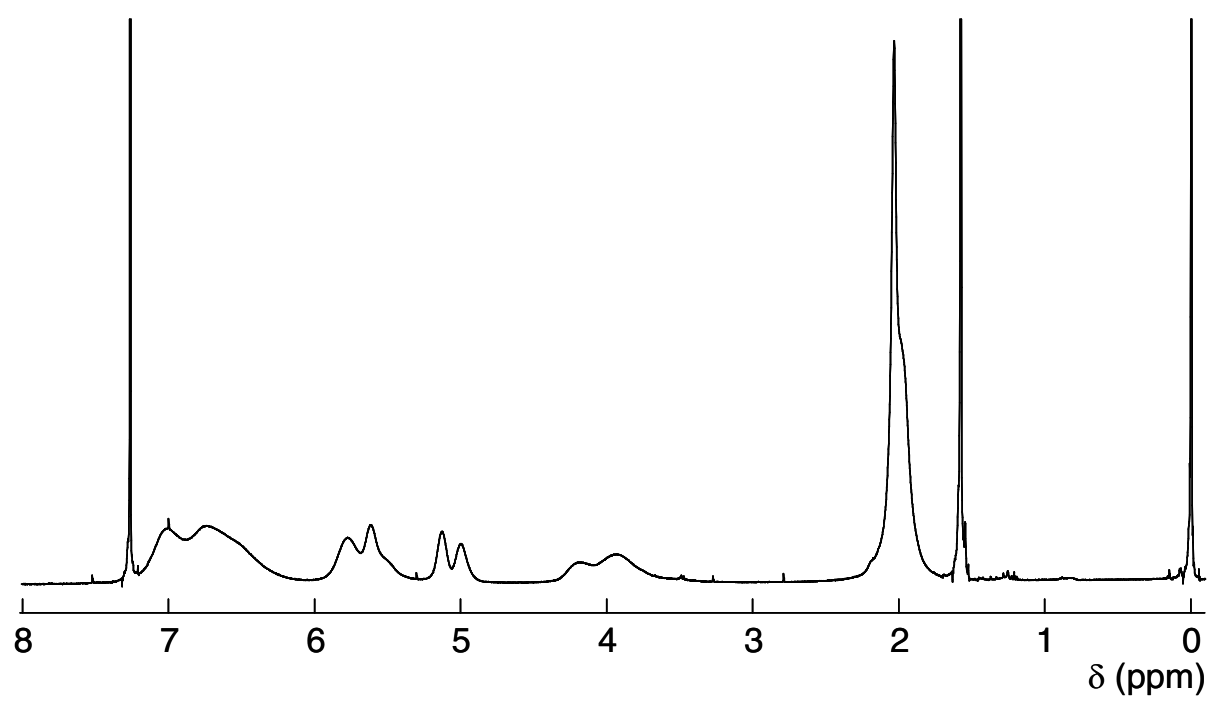

Figure S-1. ${ }^{1} \mathrm{H}$ NMR spectrum of poly $\left(\mathbf{P A}_{0.5}-c o-P A-\alpha-G l c-O A c_{0.5}\right)$ in $\mathrm{CDCl}_{3}$.

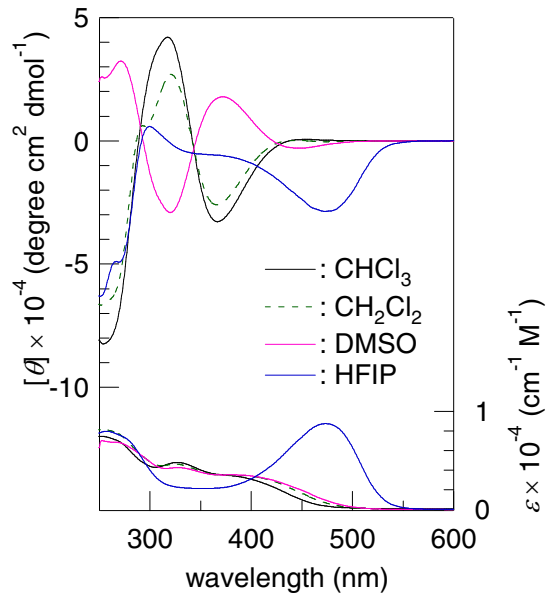

Figure S-2. $\mathrm{CD}$ (upper) and UV-vis (lower) spectra of poly-PA- $\beta$-Glc-OAc in $\mathrm{CHCl}_{3}, \mathrm{CH}_{2} \mathrm{Cl}_{2}, \mathrm{DMSO}$, and HFIP at room temperature. 


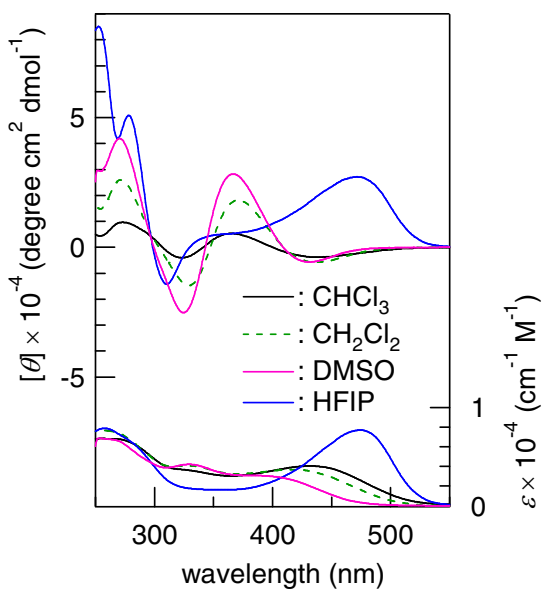

Figure S-3. CD (upper) and UV-vis (lower) spectra of poly-PA- $\alpha-G a l-O A c$ in $\mathrm{CHCl}_{3}, \mathrm{CH}_{2} \mathrm{Cl}_{2}, \mathrm{DMSO}$, and HFIP at room temperature.

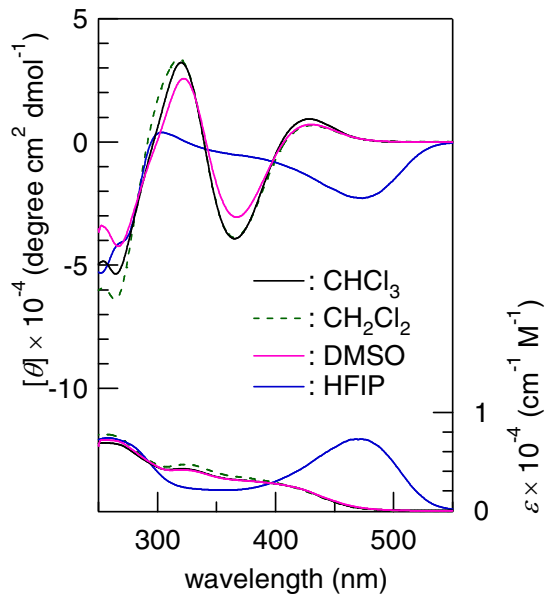

Figure S-4. CD (upper) and UV-vis (lower) spectra of poly-PA- $\boldsymbol{\beta}-\mathbf{G a l}-\mathrm{OAc}$ in $\mathrm{CHCl}_{3}, \mathrm{CH}_{2} \mathrm{Cl}_{2}, \mathrm{DMSO}_{\text {, }}$ and HFIP at room temperature. 


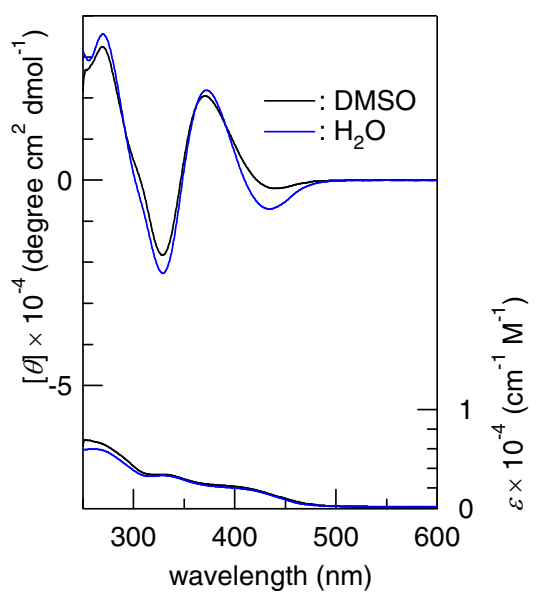

Figure S-5. CD (upper) and UV-vis (lower) spectra of poly-PA- $\alpha$-Glc in DMSO and $\mathrm{H}_{2} \mathrm{O}$ at room temperature.

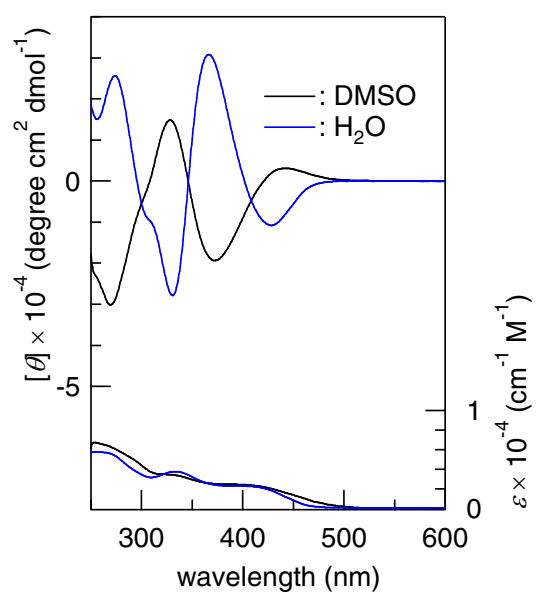

Figure S-6. CD (upper) and UV-vis (lower) spectra of poly-PA- $\beta$-Glc in DMSO and $\mathrm{H}_{2} \mathrm{O}$ at room temperature. 


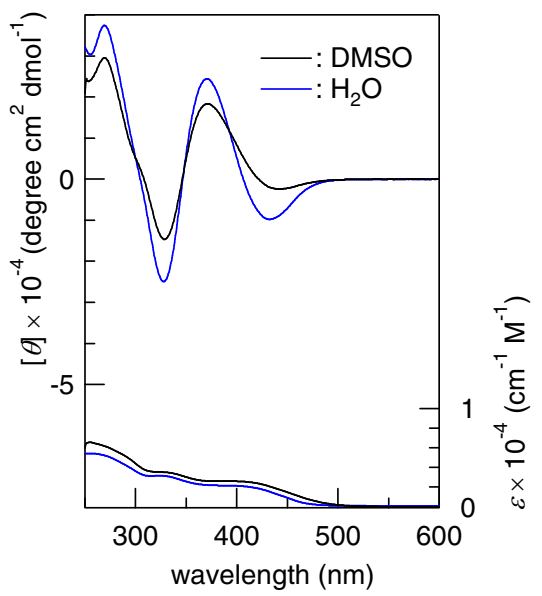

Figure S-7. CD (upper) and UV-vis (lower) spectra of poly-PA- $\alpha-G a l$ in DMSO and $\mathrm{H}_{2} \mathrm{O}$ at room temperature.

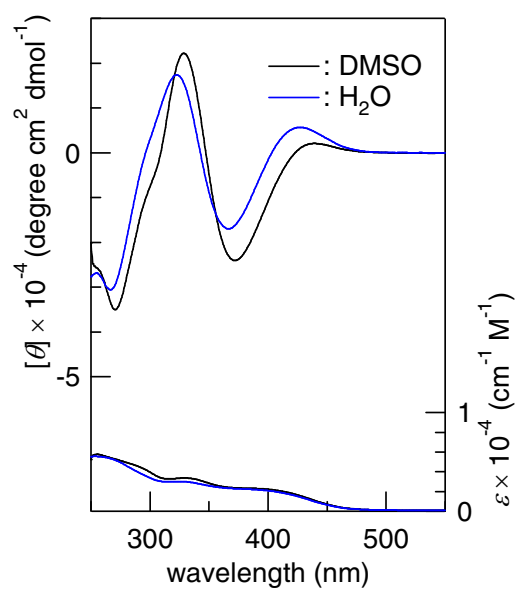

Figure S-8. CD (upper) and UV-vis (lower) spectra of poly-PA- $\boldsymbol{\beta}-\mathbf{G a l}$ in DMSO and $\mathrm{H}_{2} \mathrm{O}$ at room temperature. 